\title{
Endoscopic Management of Meningoencephaloceles and other Cranial Base Defects using Septal Cartilage
}

Raghav Mehta, Divij Sonkhya, Nishi Sonkhya

\begin{abstract}
Objective: To study and analyze 40 cases managed endoscopically of meningoencephaloceles and other cranial base defects using septal cartilage.
\end{abstract}

Design: Prospective, interventional case series.

Materials and methods: This study was conducted in the Department of Otorhinolaryngology SMS Medical College from 2006 to 2011. The study consisted of evaluations of self-reported and referred patients who presented to ENT OPD and emergency. In all the cases a detailed history and clinical examination was done. All the patients underwent nasal endoscopic examination. Computed tomographic (CT) scans were obtained for all cases. Magnetic resonance imaging (MRI) and CT cisternography was done in some of the cases.

Results: Success of the treatment was defined as resolution of symptoms, stoppage of leak, no recurrence, no complication and regular follow-up. A total of 40 cases were managed between 2006 and 2011 and were reviewed. The main presentation was of cerebrospinal fluid (CSF) leak in 22 cases with most common cause being traumatic. Fovea ethmoidalis being the most common site involved in 19 cases.

Conclusion: Endoscopic repair is the most modern and best result-oriented tool in the armamentarium of a surgeon to handle CSF leaks and with use of septal cartilage the results are less burdened with recurrences and failures.

Keywords: Cerebrospinal fluid leak, Meningocele, Meningoencephalocele, Nasal septal cartilage.

How to cite this article: Mehta R, Sonkhya D, Sonkhya N . Endoscopic Management of Meningoencephaloceles and other Cranial Base Defects using Septal Cartilage. Clin Rhinol An Int J 2013;6(2):67-71.

Source of support: Nil

Conflict of interest: None declared

\section{INTRODUCTION}

Cerebrospinal fluid (CSF) is a protective mechanism for brain produced by choroid plexus. It runs in a close network of ventricles and associated spaces, produced at a rate of $0.35 \mathrm{ml} / \mathrm{minute}$ or around 350 to $500 \mathrm{ml}$ per day. It also gets continually absorbed so that total volume in an adult male at a time is approximately 90 to $150 \mathrm{ml}$.

As CSF is in a continuous state of production, absorption and flow in a closed circuit any breach in this circuit leads to CSF being exposed to outside. This CSF leaks result from dehiscence or disruption in continuity of dura, arachnoids and bone in skull base.

If the defect is so large that meninges and brain parenchyma also herniates then meningoceles and meningoencephaloceles occur respectively.
Previously these conditions were managed by open surgical procedures. First attempt to manage these conditions was done by Dandy ${ }^{1}$ in 1926 by bifrontal craniotomy but with a high recurrence rate of almost 30\% and lots of morbidity. It was Dohlman ${ }^{2}$ who in 1948 by using a nasoorbital incision closed a cribriform plate defect. For the first time in $1952 \mathrm{Hirsch}^{3}$ used a transnasal approach. Endoscopic approach was used by Wigand ${ }^{4}$ in 1981 and he was also the first to use fibrin glue.

While previously the defect were closed with only fascia, or cartilage or bone but the recent concept used a combination of these along with the help of tissue glue. The aim of our study is to share our experience regarding endoscopic repair of CSF rhinorrhea and other skull base defects with help of septal cartilage and other materials required as per the size of the defect.

\section{MATERIALS AND METHODS}

A prospective randomized controlled study was done over a period of 5 years from 2006 to 2011 at the Department of Otorhinolaryngology and Head and Neck Surgery in association with Department of Neurosurgery at SMS Medical College, Jaipur. A total 40 cases were treated of both simple CSF leak and leak with skull base defect resulting in meningo- or meningoencephalocele.

Proper history, clinical examination, radiological evaluation and endoscopic examination were done in all the patients presenting with watery rhinorrhea with or without nasal obstruction. Radiological examination included CT scan of nose and paranasal sinus (Figs 1 and 2) in all the cases, magnetic resonance imaging (MRI) brain and computed tomographic (CT) cisternography in certain cases were obtained.

The patients were given a course of antibiotic before the procedure and maximum cases were done under general anesthesia. First and foremost aim was to identify precise location and size of defect especially if associated with a large mass. The extent of the lesion was ascertained both endoscopically and radiologically (Figs 1 to 3 ).

The patient was placed in supine position with head raised to about $15^{\circ}$. The nose was packed with $4 \%$ xylocaine with adrenaline (in ratio of 1:5) and left for around 10 minutes. After removal of pack, locally the area was injected with 2\% xylocaine and 1:2 lakh adrenalines; again a wait of 5 minutes was done to have desired effect. Next step 


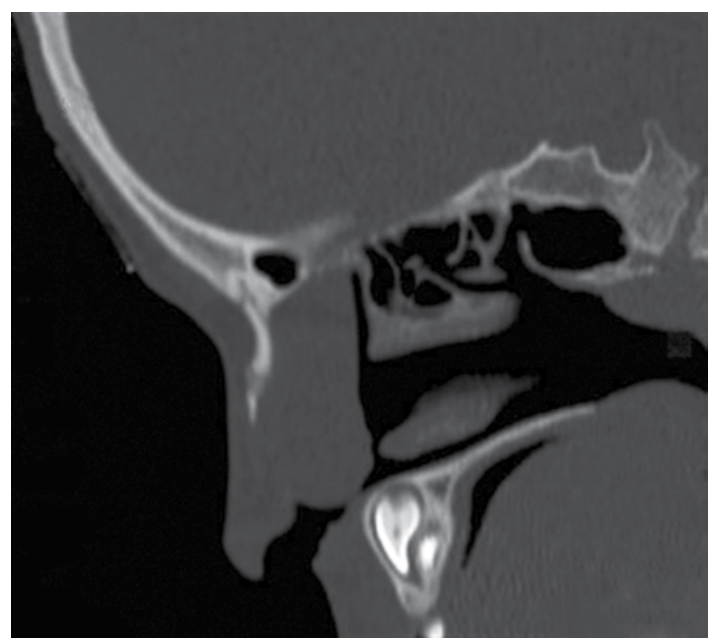

Fig. 1: CT scan (sagittal section) showing encephalocele

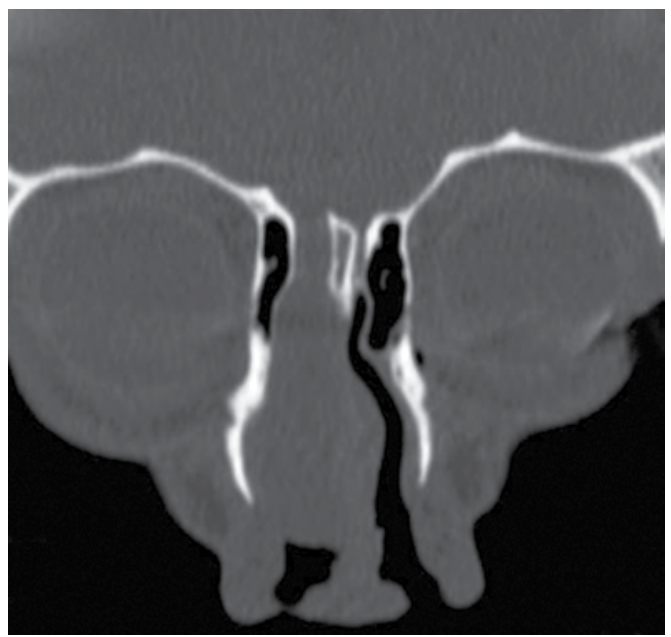

Fig. 2: CT scan (coronal section) showing encephalocele

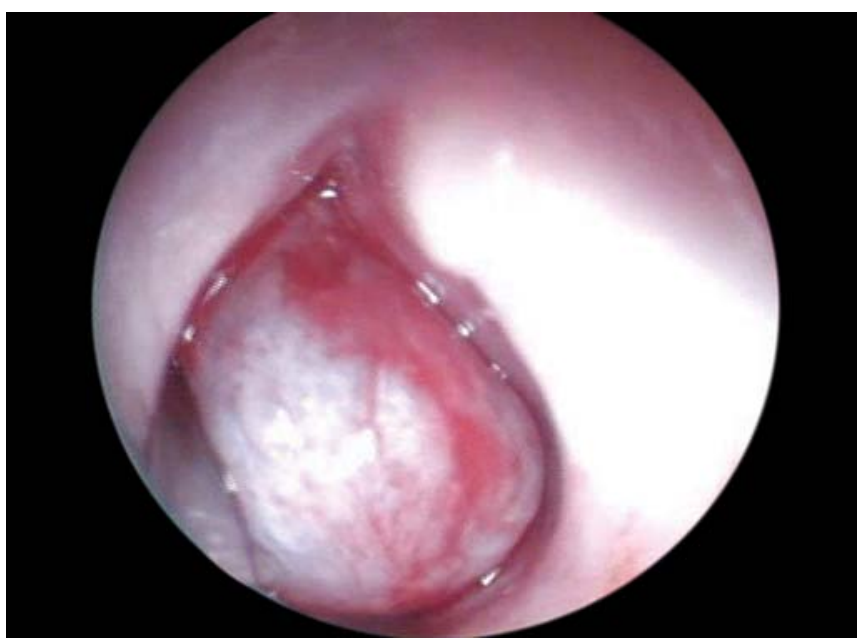

Fig. 3: Endoscopic photograph of the encephalocele

was to prepare the bed. If the defect was small and only intracranial then all that was required was to elevate the dura approximately $3 \mathrm{~mm}$ on all side. If the defect was large or extracranial, then removal of mucosa around the defect was done for a least $3 \mathrm{~mm}$ in all directions. If small meningocele or meningoencephaloceles were present then they were simply pushed inside and defect closed over them, but if large then they were removed preferably by microdebrider and in some cases with bipolar cautery (Fig. 4).

Next step was to harvest the graft material. Septal cartilage was obtained by giving incision on opposite side so that it does not interfere with the operating site (Fig. 5). Size harvested was at least $3 \mathrm{~mm}$ larger than the defect. Temporalis fascia was used along with septal cartilage for larger defects, obtained from post auricular region incision. Durafoam and fibrin glue were also used. A specific principle was followed that if the defect was $5 \mathrm{~mm}$ or more then a combination of cartilage, fascia and fibrin glue were used, but for defects less then $5 \mathrm{~mm}$, cartilage and durafoam used to suffice enough.

Septal cartilage was inserted as an inlay technique and over it extracranially temporalis fascia with fibrin glue or durafoam were kept (Figs 6 and 7). The main criteria being able to give good graft support both intra- and extracranially. For larger defects lumbar drain was kept for 5 days. The nose was packed for at least 48 to 72 hours.

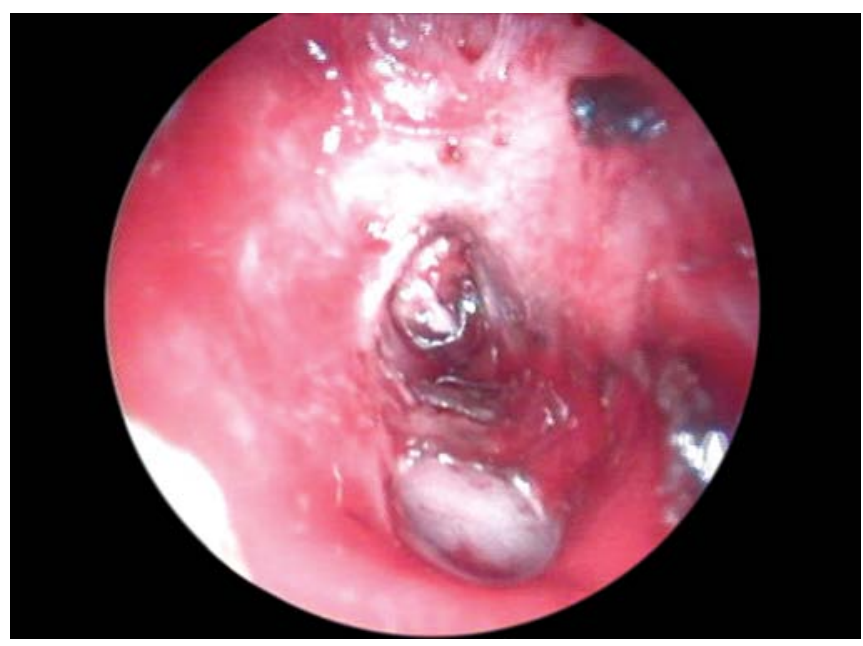

Fig. 4: Endoscopic picture showing skull base defect

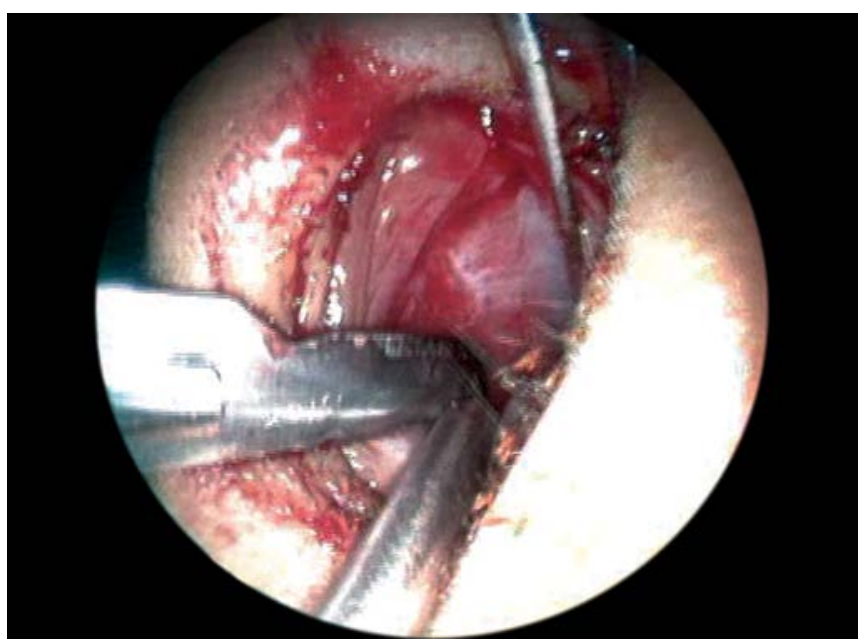

Fig. 5: Endoscopic picture harvesting septal cartilage for graft 


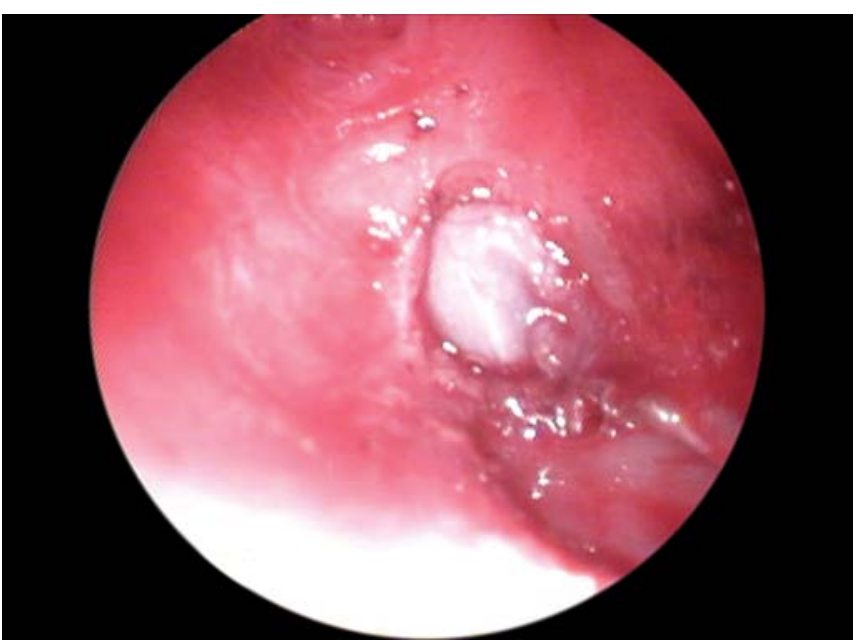

Fig. 6: Endoscopic picture showing graft covering skull base defect

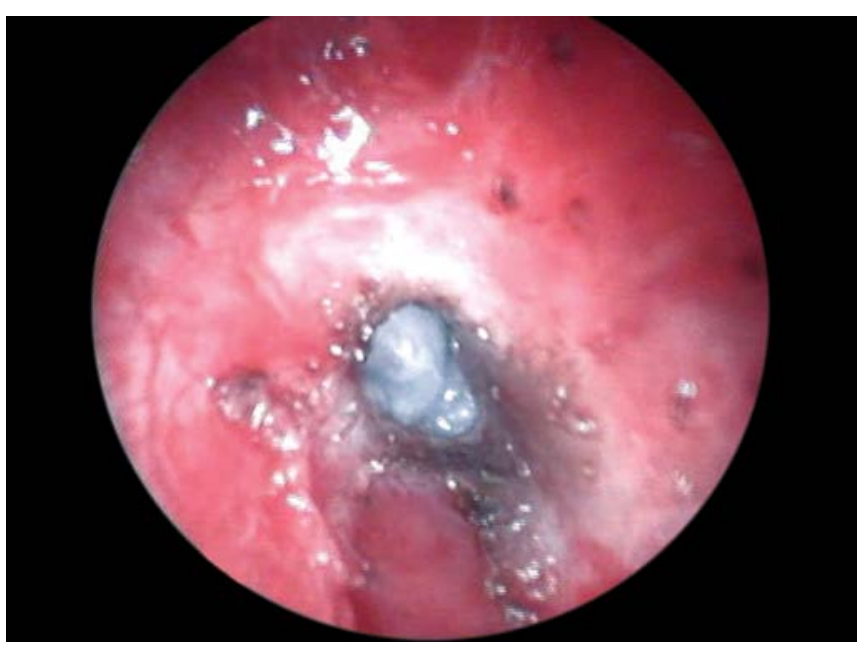

Fig. 7: Endoscopic picture showing fibrin glue over the graft covering skull base defect

Patient was kept on absolute bed rest and to avoid strenuous activity for at least 1 week. Broad spectrum antibiotic coverage was given for 1 to 2 weeks. Follow-up was done endoscopically after 2 weeks of the surgery and after another fortnight. Then the patient was called for follow-up every month for next 3 months and then 3 monthly for at least 1 year.

\section{RESULTS AND ANALYSIS}

A total 40 cases were treated in a span of 5 years, both simple CSF leak and leak with skull base defect resulting in meningo- or meningoencephalocele. A total of 29 cases were males and 11 cases were females. Twenty-two cases were presented with CSF leak, seven cases with meningocele and 11 cases with meningoencephalocele (Graph 1). A total of 23 cases were between the age group of 20 to 60 years, while 10 cases were less than 20 years and only seven cases were above the 60 years of age (Graph 2). Spontaneous leak was seen in only six cases. Iatrogenic leak was the etiology in 11 cases and rest 26 cases were of traumatic origin. Site of the leak demonstrated was fovea ethmoidalis in 19 cases, cribriform plate in 12 , sphenoid sinus in five and lateral lamella in four cases (Graph 3). Less than $5 \mathrm{~mm}$ defect was observed in 22 cases, septal cartilage and duraform was used. Septal cartilage, temporalis fascia and fibrin glue was used in 18 cases with defect $5 \mathrm{~mm}$ or more.

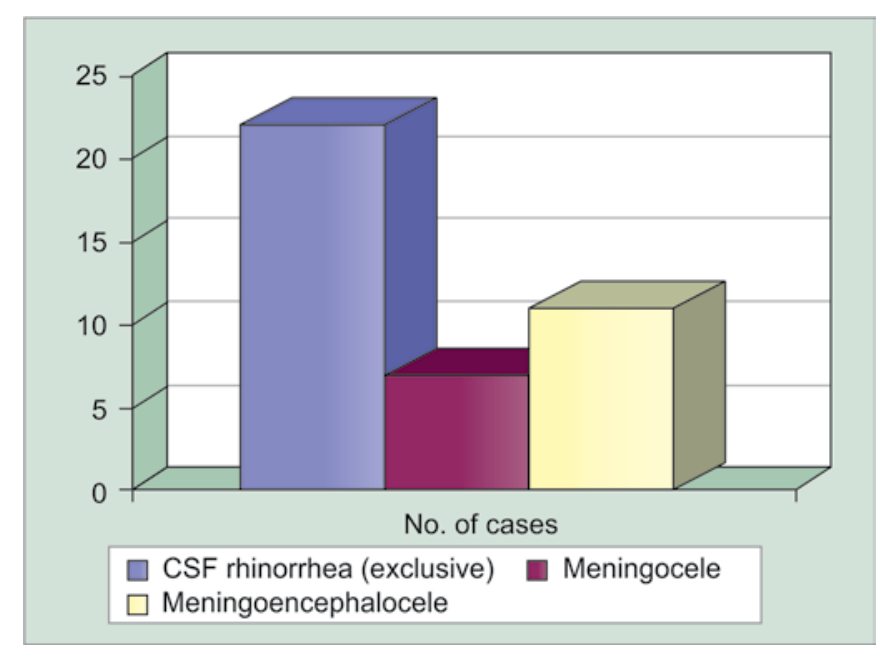

Graph 1: Distribution of patients

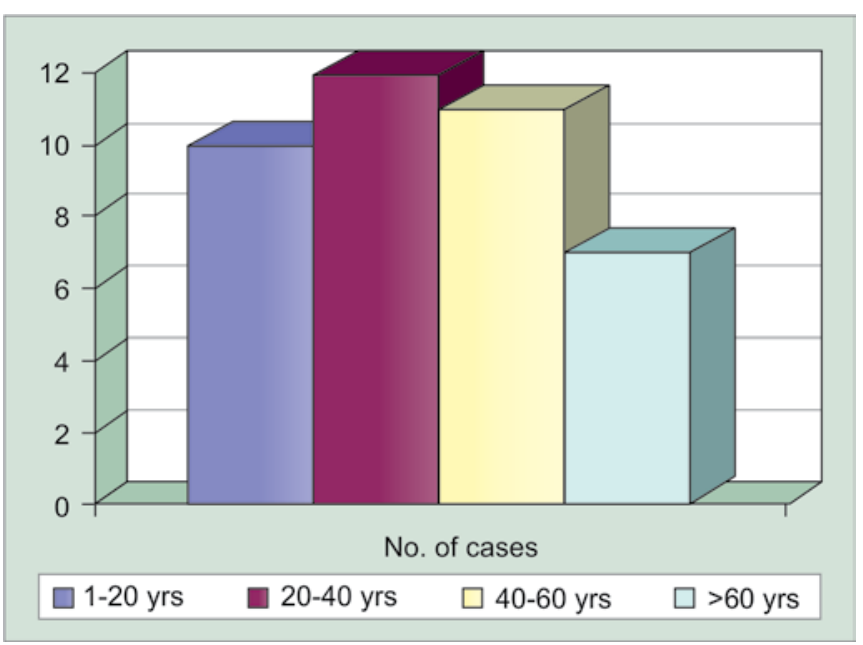

Graph 2: Age distribution of patients

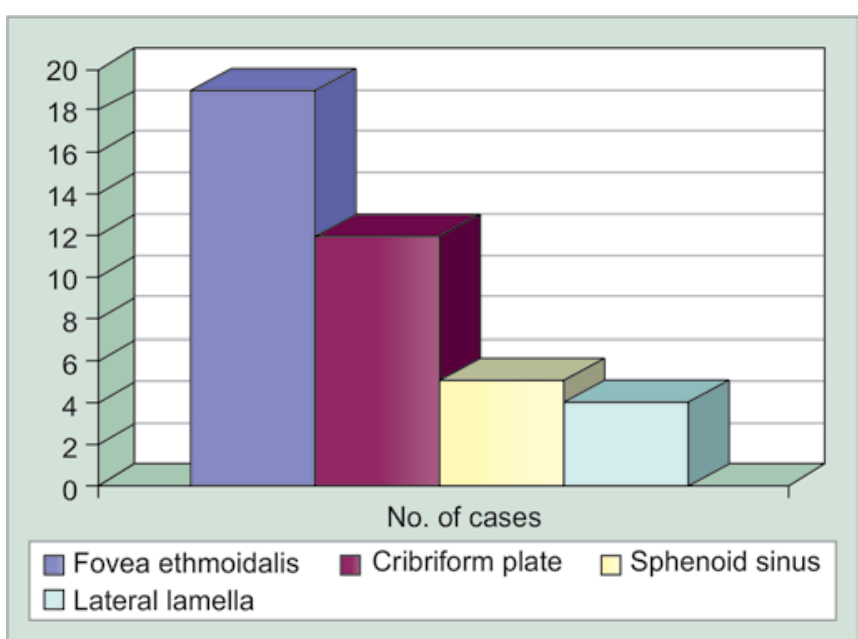

Graph 3: Sites of leak 


\section{DISCUSSION}

CSF rhinorrhea can range from a minor leak presenting as simple rhinorrhea or may progress to be a life-threatening condition causing intracranial complications like meningitis. In previous years management of CSF leaks used to be a hard fought battle with extensive and radicle surgical procedures leading to high failure rates, recurrences and a load associated morbidities. With advent of endoscope, the management of CSF leaks and cephaloceles has been revolutionized.

Endoscopic repair gives an excellent field of vision allowing precise and excellent localization of defect, avoids the complications of external approach, external incision is avoided, no handling of brain tissue, no occurrence of epilepsy, anosmia, less operative time and hospital stay, less recurrence. There is also advantage of removing the adjacent mucosa without increasing the defect size and accurate positioning of graft material is much easier.

Site of the leak depends on the etiology. In cases of traumatic leak, site may be fovea ethmoidalis, fovea ethmoidalis-olfactory fossa junction, lateral wall of sphenoid sinus or posterior table of frontal sinus. Spontaneous leak usually associated with raised ICT, can arise from cribriform plate or lateral wall of sphenoid sinus. Iatrogenic leak can arise from fovea ethmoidalis or lateral wall of olfactory fossa (medial limit of frontal recess dissection) during endoscopic sinus surgery or from sphenoid sinus during pituitary or clival surgery. Meningoencephalocele consists of meninges with dura and variable amount of brain tissue. It could be of congenital, acquired or traumatic origin.

Generally all the sites and all kind of defects can be approached through simple endoscopic approach but in few cases procedures like craniotomy with cranialization frontal sinus have to be used with the aid of neurologists, e.g. in coexisting intracranial pathology requiring excision or defect of posterior wall of frontal sinus.

In a period of 5 years we have treated 40 cases of CSF leak with or without associated meningocele or meningoencephalocele. Most commonly we found the defect to be exclusively of CSF leak with no herniation which was seen in 22 cases, in around 11 cases meningoencephalocele was seen and rest seven had meningocele. Mattox et $\mathrm{al}^{5}$ treated 27 cases and they had exclusive CSF leak in 17 cases and cephaloceles in another 10, whereas Greogry Y Chin et $\mathrm{al}^{6}$ studied 37 cases out of which six were of cephaloceles and rest of CSF leak due to various causes.

The most common site was fovea ethmoidalis followed by cribriform plate in 12 cases. P Thulasi Das et $\mathrm{al}^{7}$ also reported fovea to be the most common site in a study of 62 cases, i.e. in 24 cases and cribriform plate was involved in
13 cases whereas Mattox et $\mathrm{al}^{5}$ reported ethmoids to be the most common site in 17 and cribriform plate in six cases out of 27 cases they studied.

Spontaneous leak seemed to be the etiology in five cases in our study whereas traumatic and iatrogenic amounted to 24 and 11 cases respectively. Mattox et $a l^{5}$ had iatrogenic as the most common cause in 17 of their patients and trauma and spontaneous in three and seven cases respectively. $\mathrm{P}$ Thulasi Das et $\mathrm{al}^{7}$ reported spontaneous leak in 51 cases, nine post-traumatic and two iatrogenic.

Mattox $^{5}$ and P Thulasi Das ${ }^{7}$ used septal cartilage for the repair and reported excellent results whereas Greogry $Y$ Chin $^{6}$ used middle turbinate mucosal graft. In our study we used septal cartilage as the main graft material and further enhancing the reconstruction by covering with temporalis fascia graft and fibrin glue or durafoam according to the size of the defect. Results were good achieving $95 \%$ success rate, two cases developed leak within a week period. One of the patients was hypertensive with uncontrolled blood pressure, and other patient was a child of 9 years, who was very irritable and did not have smooth recovery from general anesthesia. This child had recurrence of leak 4 hours postsurgery. A lumber drain was also put, but there was no improvement. Revision surgery for the hypertensive patient was performed after controlling the blood pressure; patient is doing well since then. The child lost for follow-up considering the overall success rate to be $97.5 \%$.

\section{CONCLUSION}

Septal cartilage appears to be a readily available, easily harvestable, stable and moldable and a very strong support for closure of leaks. It has significantly strengthened the armamentarium of an endoscopic surgeon. With a meticulous method of precise defect identification, proper preparation of bed and judicious use of graft use and support, the endoscopic CSF leak closure has become a result oriented and successful mode of treatment.

\section{REFERENCES}

1. Dany WD. Pneumocephalus (intracranial pneumocele or aeroscele). Arch Surg 1912;12:949-982.

2. Dohlman G. Spontaneous cerebrospinal rhinorrhea. Acta Otolarynol Suppl (Stockh) 1948;67:20-23.

3. Hirsch O. Successful closure of cerebrospinal fluid rhinorrhea by endonasal surgery. AMA Arch Otolaryngol 1952;56(1):1-2.

4. Wigand ME. Transnasal ethmoidectomy under endoscopic control. Rhinology 1981 Mar;19(1):7-15.

5. Das PT, Balasubramanian D. Extradural cartilage inlay graft in cerebrospinal fluid fistula repair. J Laryngol Otol 2010 Dec;124(12):1294-1297.

6. Chin GY, Rice DH. Transnasal endoscopic closure of cerebrospinal fluid leaks. Laryngoscope 2003 Jan;113(1):136-138. 
7. Mattox DE, Kennedy DW. Endoscopic management of cerebrospinal fluid leaks and cephaloceles. Laryngoscope 1990 Aug;100(8):857-862.

\section{ABOUT THE AUTHORS}

\section{Raghav Mehta}

Senior Resident, Department of ENT, SMS Medical College and Attached Hospitals, Jaipur, Rajasthan, India

\section{Divij Sonkhya}

Resident, Department of ENT, NKP Salve Institute of Medical Sciences, Nagpur, Maharashtra, India

\section{Nishi Sonkhya (Corresponding Author)}

Professor, Department of ENT, SMS Medical College and Attached Hospitals, Jaipur, Rajasthan, India, e-mail: drsonkhya@yahoo.co.in 